\title{
Mathematical Motivators: Using the history of mathematics to enrich the curriculum
}

\author{
Mark McCartney \\ School of Computing and Mathematics \\ University of Ulster \\ m.mccartney@ulster.ac.uk
}

Project website and deliverables: www.inf.ulst.ac.uk/ mmccart/hom.htm

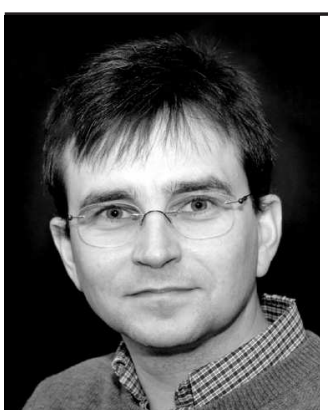

Noel-Ann Bradshaw

School of Computing and

Mathematical Sciences

University of Greenwich

n.bradshaw@gre.ac.uk

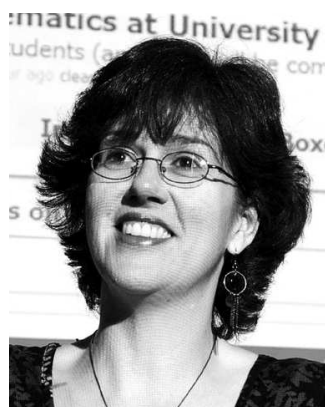

Tony Mann

School of Computing and

Mathematical Sciences

University of Greenwich

a.mann@gre.ac.uk

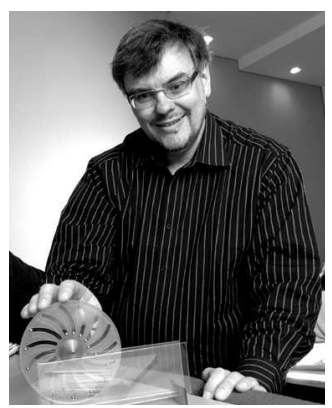

\section{Introduction}

This article provides a summary of the MSOR funded mini project Mathematical Motivators.

Mathematics is usually, and of course correctly, presented 'ready-made' to students, with techniques and applications presented systematically and in a logical order. However, like any other academic subject, mathematics has a history which is rich in astonishing breakthroughs, false starts, misattributions, confusions and dead-ends. This history gives a narrative and human context which adds colour and context to the discipline.

The authors have noted in their own teaching that motivating students to the study of a new topic in mathematics can often be helped by setting the subject in a historical context. Indeed, it has been shown by Hagerty et al [1] that 'the inclusion of historical modules caused positive changes in mathematical communication, student achievement and attitudes'. This echoes the views of many other academics and educators [2].

Setting historical context can motivate and enthuse learning, but it also enriches the curriculum, shows connections between different branches of the subject, and helps to produce students with a greater sense of the breadth and, what might be termed, the creative life of mathematics as a discipline. We believe that many lecturers would like to include historical elements in their courses but lack the subject knowledge, the confidence to engage with history, or the time to prepare such material.

There are of course many valuable resources on the history of mathematics, and in particular the MacTutor history of mathematics website, created by E. F. Robertson and J.J. O'Connor, is widely used by academics and students [3]. Resources like MacTutor provide a great deal of information but we feel that there is a demand for 'bite-sized' resources specifically relating to the undergraduate curriculum. The MacTutor article on Newton, for example, naturally runs to six close-packed pages, which would not easily fit into a lecture on calculus. As van Brummelen notes, "school teachers and educational associations demand easily digested 'sound bites' that may be inserted with little fuss into an existing curriculum"[4], and the requirements of those teaching mathematics to undergraduates are similar.

The overall aim of this project was the creation of a set of 'stand alone' two page documents on a range of topics from the history of mathematics to supplement, and help motivate the teaching of, mathematical topics covered in the undergraduate curriculum. These documents are enhanced by presenting the material in $\mathrm{mp} 3$ 
format to support different learning styles and meet the expectations of today's students, many of whom use mobile devices to listen to podcasts and other resources while travelling to university and at other times. Podcasts such as Math/Maths [5] and Travels in a Mathematical World [6] have gathered a following amongst undergraduate mathematicians. One member of the project team $(\mathrm{N}$. Bradshaw) provided a series of history of mathematics podcasts for the latter, which were favourably received by students, and some of which provided a starting point for this project.

We have provided resources to facilitate the inclusion of historical material in modules covering mathematical methods and ideas in both mathematics degree programs and service teaching. The materials are not designed for use by academics teaching modules on mathematics degrees which are specifically on the history of mathematics, where a more complex analysis of the issues would be required.

We use the term 'reusable learning objects' (RLOs) to describe these documents and mp3 files as each is relatively brief, self contained and independent of each other, providing an efficient way for teachers to embed the materials into their lecture courses and supporting teaching websites.

\section{Project Deliverables}

The project deliverables can be found at the homepage www.inf.ulst.ac.uk/ mmccart/hom.htm

These web pages comprise twenty 2 page 'bite-sized' learning resources, in pdf format, and twenty accompanying audio files in $\mathrm{mp} 3$ format on the following topics:

- Archimedes

- From Beans to Bytes: A History of Calculating Machines

- Complex Numbers

- Einstein and Relativity

- Leonhard Euler

- Fibonacci

- Jean Baptiste Joseph Fourier

- Évariste Galois

- Gödel's Incompleteness Theorems

- Islamic Mathematics

- Pierre Simon de Laplace

- The Logistic Map

- Colin Maclaurin \& Brook Taylor

- Nevil Maskelyne and Leslie Comrie - Pioneers of Automated Mathematics

- Mathematical Notation

- Isaac Newton
- Florence Nightingale

- Non-Euclidean Geometry

- $\pi$

- The Schrödinger Equation

Each pdf comprises an appropriate image (sourced from Wikimedia Commons to avoid copyright issues), narrative and, where appropriate, suggestions for further reading. The pdfs also have a common identifying graphic designed by Adam Sebestyen (Fig 1), an undergraduate at the University of Greenwich. The mp3 files are a reading based on the corresponding pdf, each lasting between 6-8 minutes.

\section{HISTORY}

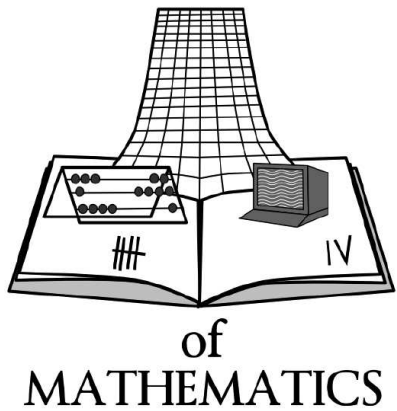

Fig 1 - History of Mathematics logo designed by Adam Sebestyen

The selection of topics reflect both the range of mathematical sciences and its antiquity and are designed to fit within the undergraduate curriculum. They are designed to provide background to topics like calculus or complex numbers, address the perception amongst some undergraduates that computing is not relevant to a maths degree, or give biographical information about mathematicians such as Euler whose names will arise in many different modules in the early stages of a maths degree.

\section{Feedback}

Feedback from undergraduates who have used early versions of these materials has been very positive, with comments including: "I want to do maths because I am inspired by knowing about the people behind it"- First year mathematics undergraduate 2010, Greenwich. Or, listed as one of the three best things about the module; "The extra information about people like Newton." - First year engineering undergraduate 2010, Ulster.

We note that in both these cases the comments were made as part of the overall module evaluation process i.e. the students were not specifically prompted for their views on the history of mathematics materials which had been embedded in the lecture notes. The fact that students drew positive attention to the materials 'unprovoked', as it were, is itself encouraging. Further feedback will be obtained in future from students and tutors, and a hyperlink has been added to the project web pages inviting feedback from users. 


\section{Future Developments}

The format of the materials produced lends itself to the extension of the range of topics covered so far and it is hoped that over the next 18 months more titles will be added.

Building on the success of the mp3 files, more sophisticated audio-visual presentations for mobile devices could provide an even richer resource.

\section{"Setting historical context can} motivate and enthuse learning, but it also enriches the curriculum, shows connections between different branches of the subject, and helps to produce students with a greater sense of the breadth and, what might be termed, the creative life of mathematics as a discipline."

The recording devices used during the project are highly portable and current software enables $\mathrm{mp} 3$ files to be efficiently manipulated using desk top editing. Both these points lend themselves to experimenting with producing oral histories of British mathematics via structured interviews with academics. There are some isolated examples of oral history in mathematics (see for example $[8,9,10]$ ) and there are plans to make available via the Internet the Michael Wright Archive of sound recordings which largely consists of recordings of lectures and seminars etc [11]. But there does not appear to be anything on the (still relatively modest) scale of what has been done by the physics community [10,12], where even here the majority of material available is in transcript format. We are hopeful that the hardware and software used during the current project can be further used to start to create a publicly available oral history of mathematics in the second half of the 20th century. Finally, a more detailed report on the project can be found in the CETL_MSOR 2010 Conference proceedings [13].

\section{References}

1. G.W. Hagerty, S. Smith, and D. Goodwin. (2007), The Unique Effects of Including History in College Algebra. Convergence: Where Mathematics, History and Teaching Interact. USA: MAA

2. V.Katz (Ed) (2000), Using History to teach mathematics - An international Perspective. USA: MAA

3. J.J. O'Connor and E.F. Robertson, The MacTutor History of Mathematics Archive, http://www-history.mcs.st-and. ac.uk/ [last accessed January 2011]
4. G. Van Brummelen, (2010) Filling in the short blanks: musings on bringing the historiography of mathematics to the classroom, BSHM Bulletin: Journal of the British Society for the History of Mathematics, 25(1), $2-9$.

5. S. Hansen and P. Rowlett, Pulse-Project Math/Maths Podcast: 5136 miles of mathematics, http://www.pulseproject.org/pulsemathsmaths/ [last accessed January 2011].

6. P. Rowlett (Ed), Travels in a Mathematical World (podcast), http://www.travelsinamathematicalworld. co.uk/ [last accessed January 2011].

7. N. Bradshaw (2010), Communicating History of Mathematics, Mathematics Today 46(5), 249.

8. Seeley G. Mudd Manuscript Library, Princeton University, The Princeton Mathematics Community in the 1930s: An Oral-History Project, http://www. princeton.edu/ mudd/finding_aids/mathoral/pm02. htm [last accessed January 2011]

9. Simons Foundation, An Oral History Project, https:// simonsfoundation.org/mathematics-physical-sciences/ oral-history-project [last accessed January 2011]

10. Caltech Online Digital Archive, Caltech Archives Oral Histories Online, http://oralhistories.library.caltech. edu/view/subjects/sub.html [last accessed January 2011]

11. J. Barrow-Green (personal communication)

12. Niels Bohr Library \& Archives, Oral History Interviews in Physics, Astronomy and Geophysics: Online Transcripts, http://www.aip.org/history/oral_history/transcripts. html [last accessed January 2011]

13. N. Bradshaw, M. McCartney and T Mann (2011), Using history in mathematics teaching - some open educational resources for the future, CETL-MSOR 2010 Conference Proceedings, in press. 